\title{
The Tres Tabernae archeological site (Cisterna di Latina, Italy): new evidence revealed through an integrated geophysical investigation
}

\author{
Stefano Urbini ${ }^{1}$, Carla Bottari ${ }^{1{ }^{\star}}$, Marco Marchetti $^{1}$, Lili Cafarella ${ }^{1}$ \\ ${ }^{1}$ Istituto Nazionale di Geofisica e Vulcanologia, Sezione Roma 2, Rome, Italy
}

\author{
Article history \\ Received July 28, 2010; accepted November 5, 2010. \\ Subject classification: \\ Archeology, Ground-probing radar, Frequency-domain electromagnetic induction, Magnetic survey, Buried remains.
}

\section{ABSTRACT}

"Mercator» (Medocc, INTERREG IIIB) is a European project that is aimed at a detailed investigation of the historical and archeological heritage of the Mediterranean area. Within this project, broad research is being financed regarding the importance of the development of the main ancient merchant routes in this region. These various tasks include this integrated geophysical survey at the Tres Tabernae site, an ancient statio along the Appian way (close to Latina, central Italy). This was carried out using several techniques that are focused on the identification of buried archeological remains. The main goal of this investigation was to cover the area surrounding this partially excavated site to obtain a quick, but meaningful, result relating to the presence of interesting buried features. For this, the geophysical techniques involved were frequency-domain electromagnetic induction, groundpenetrating radar, and magnetometry. To obtain the best results, these methods were optimized, taking into account the kind of structures involved and their relation to the environmental context. The combination of these different geophysical techniques shows good results, indicating the possible presence of new buried structures, such as walls, floors and a lead pipe.

\section{Introduction}

Near-surface geophysical prospecting provides a fast, non-invasive and low-cost tool that is very useful for obtaining information about buried archeological evidence. The integration of different techniques also allows reduction of their typical measurement ambiguities [Brizzolari et al. 1992]. This kind of survey provides information to archeologists about the positions of interesting structures that can be investigated more thoroughly and excavated at a later date.

"Mercator» (Medocc, INTERREG IIIB) is a European project that has the aim of deeply investigating the historical and archeological heritage of the Mediterranean area. One of the targets of this project is to collect information about the importance of the main ancient merchant routes. In this framework, an integrated geophysical survey was planned and performed at a (partially excavated) site known as Tres Tabernae (at Cisterna di Latina, central Italy), a Roman statio that had a very important role in the distribution of goods along the main merchant routes, such as the Appian way.

For the application of integrated survey techniques, and taking into account the budget that might be available, two main approaches are possible [e.g. Hesse 1999, Urbini et al. 2007]. The first is a state-of-the-art routine survey of an area, where all of the geophysical techniques are used to systematically cover the whole area. This is a very efficient method, but at the same time, it can be very expensive and time consuming. The second approach consists of a preliminary analysis of a large area using only one method (which would be the fastest and the most effective amongst those available); on the basis of the results obtained, other geophysical techniques can be planned, focusing on any areas of anomaly.

Often, archeological surveys have to be carried out on private terrain over a very short period and with limited access. In the present case, we had only one day to acquire the most meaningful data possible in the surroundings of the excavated area. As a consequence, the second approach was chosen to evaluate the extent of the archeological site and to individuate the main buried structures.

This photo-geological analysis identified an area of interest around the excavated site (Figure 1), so we performed a preliminary analysis using frequency-domain electromagnetic methodology (FDEM). In a second step, the results were thoroughly investigated using ground-probing radar (GPR), along with magnetic methodology. Each single technique was carried out within a differential (European Geostationary Navigation Overlay Service, EGNOS) corrected global positioning system (GPS) positioning grid. This allowed us to compare and combine the different subsurface geophysical responses, to maximize the significance of the measurements and to reduce the ambiguities associated with each of the geophysical methods.

\section{The archeological site}

The importance of the Tres Tabernae site arises from its use as an integrated system for the distribution and sorting of goods. In the past, its location was a matter of debate 


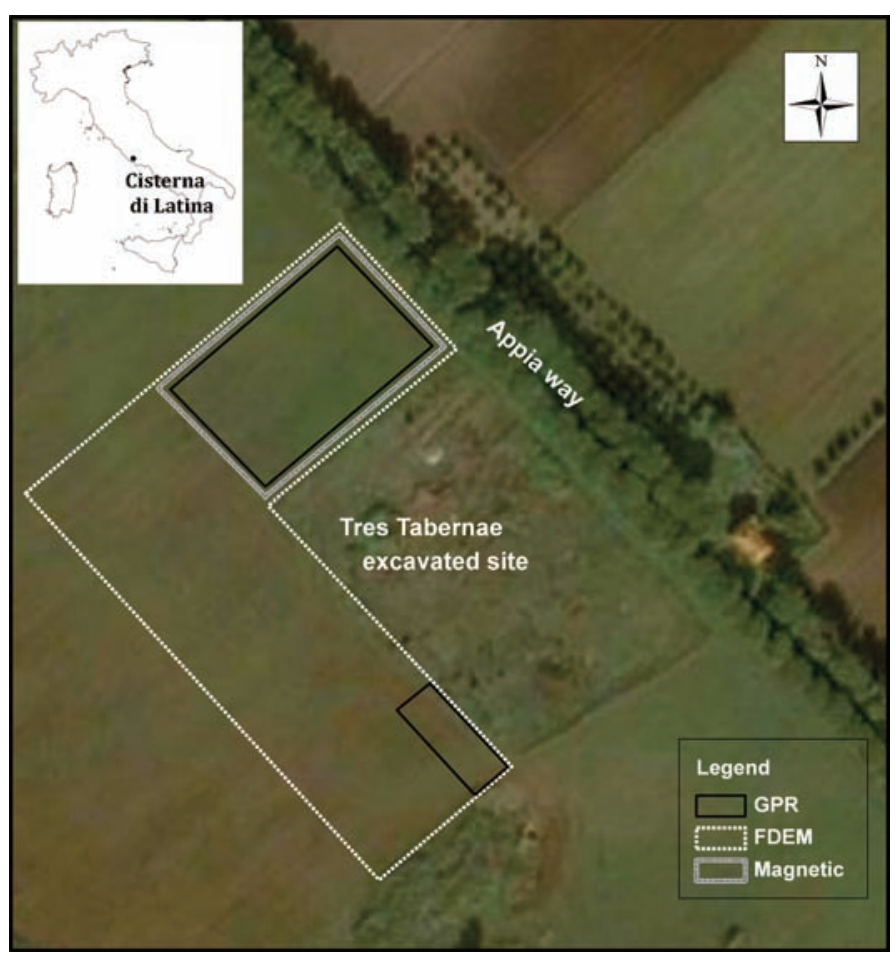

Figure 1. Map of the Tres Tabernae statio and the location (inset) of the areas investigated by these geophysical techniques (photograph from Google Earth).

between historians, although today it has been located as between the 58th and 59th $\mathrm{km}$ along the Appian way.

The first mention of Tres Tabernae appeared in some letters sent by Cicerone to Attico, between $61 \mathrm{BC}$ and $59 \mathrm{BC}$. In the Acts of the Apostles, Tres Tabernae is also remembered as a small village; in describing the journey of St. Paul from Pozzuoli to Rome (in $61 \mathrm{AD}$ ), Zosimo mentioned Tres Tabernae as the place where the Emperor Massenzio strangled Severo Cesare [Barbetta 2008]. In the Tabula Peutingeriana, of the 4 th century AD, Tres Tabernae is mentioned as one of the stationes (stop stations) that was built along the Appian way. The stationes were fiscal structures that were linked with the sorting of goods and maritime traffic. The statio of Tres Tabernae has been definitively and strictly linked with the economical activities between the nearby harbors of Terracina and Anzio and the ancient cities, whereby the goods that were brought in by ships were sorted in the inland localities through the road network. The stationes were usually located at one day of travel from one another, and they were used by travelers to rest and to change horses. The larger and more important structures were known as the mansio, which were also provided with hospitia (hotels), stabula (stalls) and shelter for the means of transport. The towns with these structures were important trading sites, and they assumed great importance because of their harbors (or their nearness to them). The Tres Tabernae site was classified as a statio, but because of its extent (estimated from the excavated remains), it might also be defined as a mansio [Barbetta 2008].

During the 6th century AD, after the Longobard invasion, the site was almost abandoned. From the mid-8th century to the mid-9th century $\mathrm{AD}$ it expanded and flourished again. A decline then started shortly afterwards, with the reappearance of the disease of malaria.

Recent archeological investigations have revealed interesting ruins that have been dated from the 1 st to the 9 th century AD. Most of the buildings had public, commercial and functional characteristics. A tract of a paved road was also uncovered, which is perpendicular to the Appian way, and which allowed access to the statio. Other remains refer to a residential building with mosaic floors [Barbetta 2008]. The buildings were made mainly from lava and tuff (from the Colli Albani volcanic complex), and limestone and travertine.

The investigated area is today agricultural terrain, where human activities have produced large modifications and have destroyed the remains of the ancient complex.

\section{Geophysical methods}

\section{Frequency-domain electromagnetic methodology}

Although FDEM has been rarely applied to archeological investigations, as can be seen by the lack of such documentation in the literature, FDEM is an easy-toimplement method in the field. Despite its low resolution characteristics, it represents a good tool to characterize an area of interest and to plan other more specific geophysical surveys [Jordan and Costantini 1999]. The application of FDEM does not require ground contact, thus it can be used to cover large areas in a short time.

FDEM is based on the induction of eddy current loops in the ground that can introduce an alternating current flow in transmitter coils. The intensity of the induced eddy currents is directly proportional to the terrain conductivity in the proximity of the loops. The induced current loops generate a secondary magnetic field that is proportional to the value of the primary field. A receiver coil placed at a specific distance from the transmitter can measure the secondary magnetic field both in quadrature $\left(90^{\circ}\right.$ out of phase) and in in-phase components, with respect to the primary field. The quadrature value is related to the ground conductivity characteristics (in milliSiemens per meter), while the in-phase component (measured in parts per thousands or millions) is significantly more sensitive to the presence of metallic objects.

Measurements can be taken by keeping the coils horizontal (vertical dipole mode) or vertical (horizontal dipole mode). The relative contributions to the secondary magnetic field at different depths of the conductive/resistive contrasts in any buried material is different in these two cases: in the vertical-coil arrangement, the influence of the surface is negligible; whereas in the horizontal mode, it has its maximum contribution.

In the case of archeological applications, buried ruins usually contribute through an increase in the resistivity of the 
hosting media [Tite and Mullins 1970, Simpson et al. 2008]. In our field work, we used a Geonics EM31-MK2 system (operating frequency, $9.8 \mathrm{KHz}$; intercoil spacing, $3.66 \mathrm{~m}$ ), which offers averaged measures of ground electrical conductivity variations of the first 3-4 $\mathrm{m}$ depth (as horizontal dipole mode).

The FDEM survey was conducted in a NW-SE direction, with a continuous acquisition rate of $1 \mathrm{~Hz}$ (see Figure 2b, inset map). The dataset were interpolated using the Kriging method [Abramowitz and Stegun 1972] with a linear variogram.

\section{Ground-probing radar}

The GPR method is based on the reflection of an electromagnetic wave due to one or more discontinuities in the dielectric properties of the subsurface media. Buried shallow walls and holes generate good contrast in the dielectric properties of the field, which can provide a target for this GPR method [e.g. see Basile et al. 2000]. The use of antennas with different frequencies allows the subsoil to be examined at different depths and with different resolution. The use of GPR in archeology has increased over the last decade or so, and it has been well documented [e.g. Pérez Gracia et al. 2000, Conyers 2004, Francese et al. 2009].

In this survey, a Geophysical Survey System Inc. Sir 10B instrument was used, which was equipped with $400-\mathrm{MHz}$ monostatic antennas. The GPR measurements were acquired along SE-NW parallel profiles that were 40-m long and spaced at 1-2 $\mathrm{m}$ (Figure 3), with an along-the-line sampling of about 100 scans $/ \mathrm{m}$. More than $2.7 \mathrm{~km}$ of GPR lines were collected, processed (horizontal normalization, frequency band-pass filtering, and gain adjusting) and interpreted. The analysis of the hyperbola diffraction conducted on the profiles led to the determination of an averaged electromagnetic-wave propagation speed of about $0.07 \mathrm{~m} / \mathrm{ns}$ in both areas. Considering the recording range, the effective investigation depth was about $2 \mathrm{~m}$ from the surface. Interpretation of the results took into account the magnitude and shape of any anomalies, and their alignment and consistency on the parallel and perpendicular lines. GPR three-dimensional imaging is a profitable technique to successfully map buried archeological remains [e.g. Piro et al. 2001, Seren et al. 2007, Francese et al. 2009], although it generally costs a lot in terms of data acquisition and postprocessing elaboration, and it often turns out to be time consuming. Nevertheless, this three-dimensional profile analysis can discriminate if a target structure is present or not in a surveyed area.

\section{Magnetic survey}

This technique passively measures the near-surface variations in the Earth magnetic field, which can reveal contrasts in the magnetic properties of the soil due to induction and remnant magnetization [e.g. Breiner 1973, Weymount and Huggins 1985, Aspinall et al. 2008, Smekalova et al. 2008].

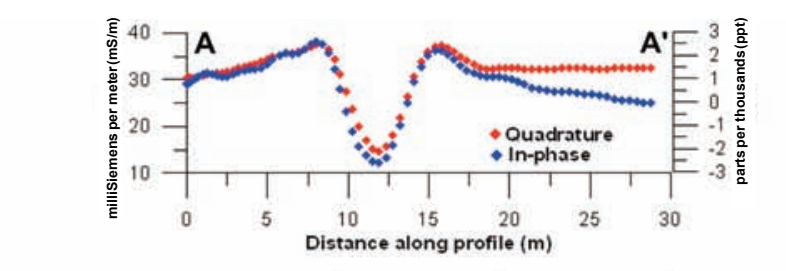

a)

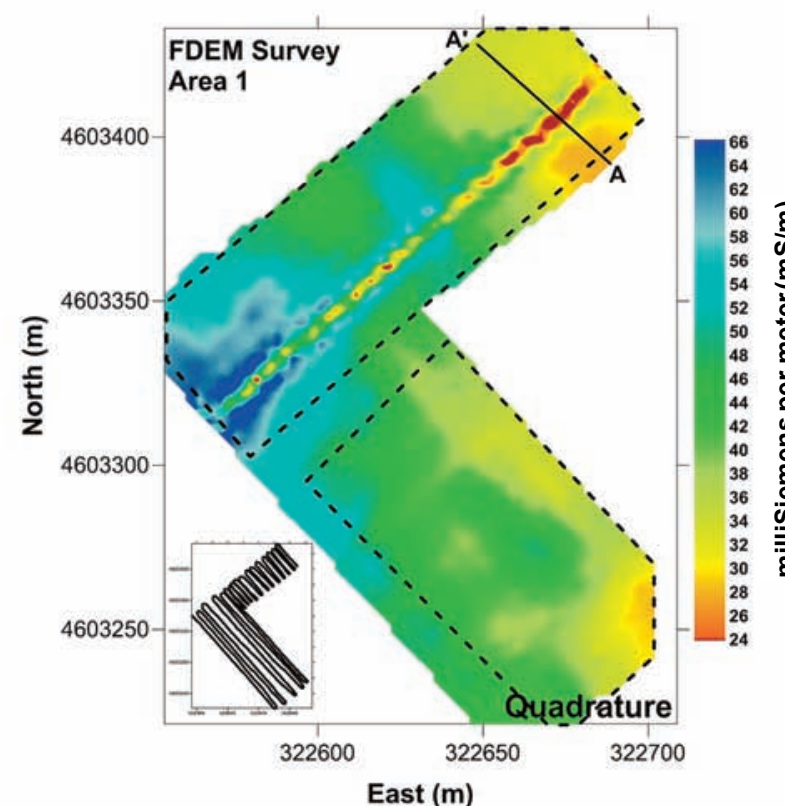

b)

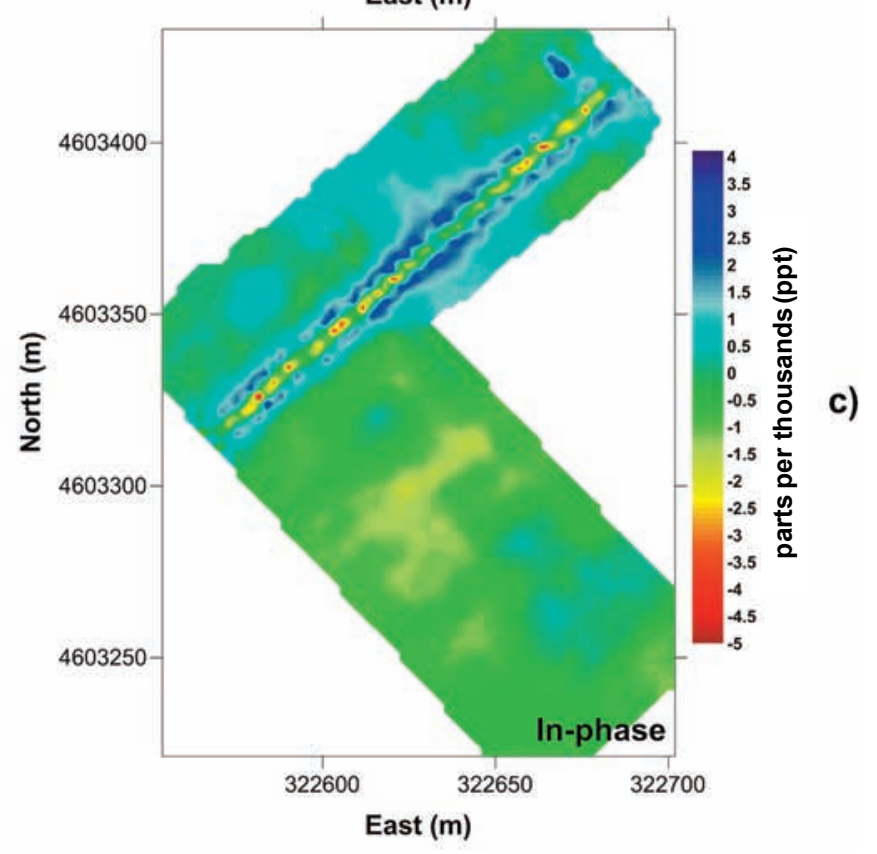

Figure 2. Map from the FDEM survey. (a) Quadrature and in-phase components along profile A-A'. (b) Map of the quadrature component. Inset, FDEM measurement profiles. (c) Map of the in-phase component.

These magnetic surveys are very effective in the archeological field because the presence of human activities produces alterations in the natural magnetic properties of the ground. Moreover, nowadays magnetometers are of ultra-high sensitivity, and they can have very fast acquisition rates. In archeological investigations, vertical gradiometric arrangements are the most usual measurement configurations (as a rule of thumb), and they consist of the simultaneous measurement of the Earth magnetic field through two sensors that are 


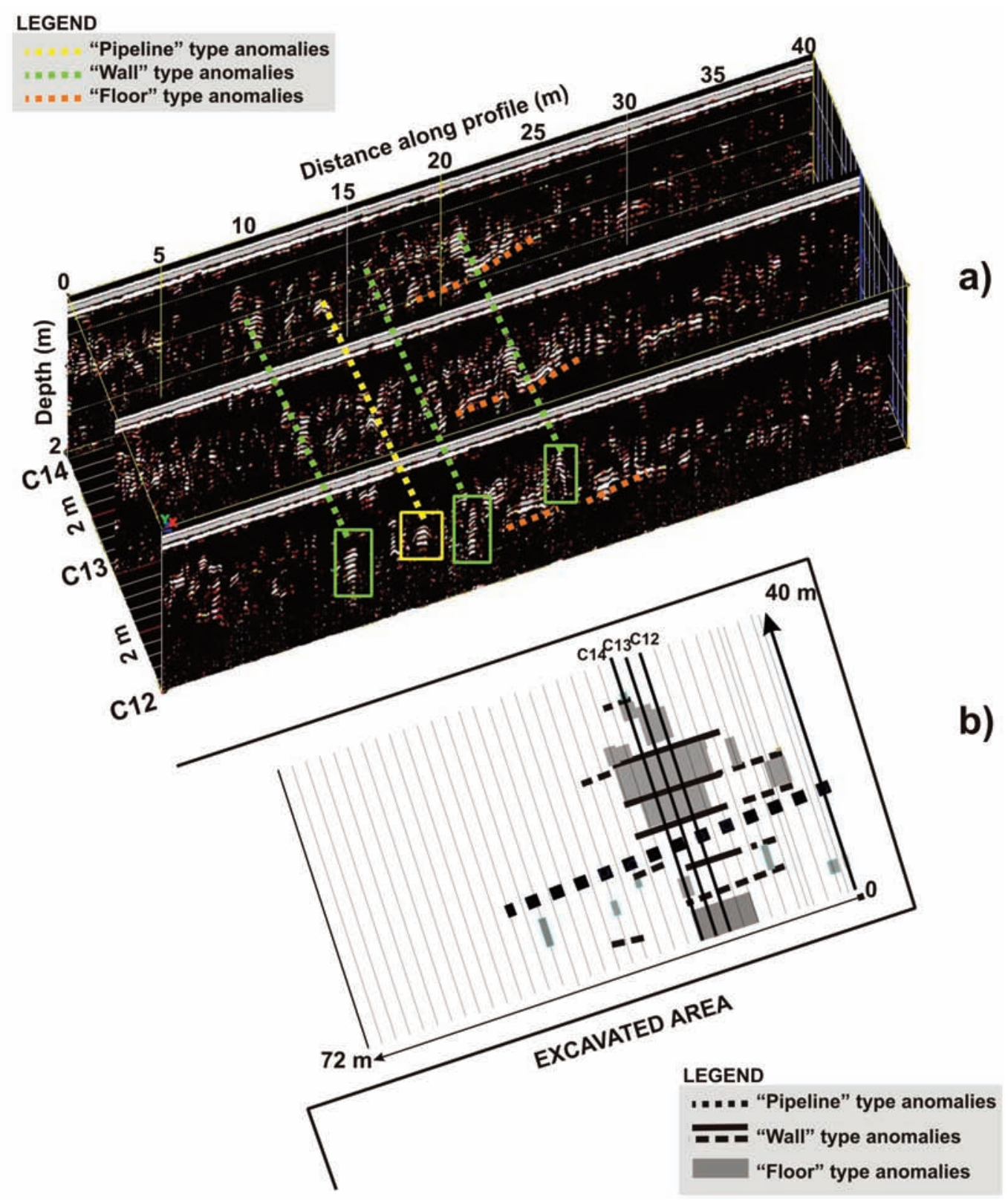

Figure 3. Map from the GPR survey. (a) Example of the anomaly consistency along three profiles (C12, C13, C14). (b) Planimetry of the main GPR anomalies.

positioned with a fixed vertical distance between them.

Due to the possibility of collecting high-density measurements, this magnetic method provides good resolution for the identification of many buried anthropogenic structures, such as buried walls, pottery, bricks, fire pits, pathways, and shallow tombs, and numerous others buried objects.

In the present investigation, the magnetic data were collected using a Geometrics G858 optical pumped cesium magnetometer in a vertical gradiometric configuration (two sensors mounted on a staff at $30 \mathrm{~cm}$ and $90 \mathrm{~cm}$ from the soil). The magnetic data were acquired along NW-SE oriented lines, with a continuous acquisition rate of $1 \mathrm{~Hz}$ (Figure 4). The quality of the collected data was good enough to avoid any specific noise canceling processes, and they were thus grided using the Kriging method (linear variogram) [Abramowitz and Stegun 1972].

\section{Main results}

This integrated geophysical survey that was carried out on the archeological site of Tres Tabernae covered a total surface area of about 1.4 ha. All of the maps reported here are in Universal Transverse Mercator (UTM) projection (zone 33N, datum WGS 84).

The preliminary FDEM measurements were analyzed along each single profile and on a two-dimensional map representation, after spatial interpolation. The single profiles indicated a strong anomaly in both the quadrature and the in-phase components of the secondary electromagnetic field. In Figure 2, an example of these anomalies is shown: the red diamonds represent the measured quadrature values, while the blue diamonds represent the in-phase component. The shape and the extension of the anomaly was typically related to the presence of a buried metallic 


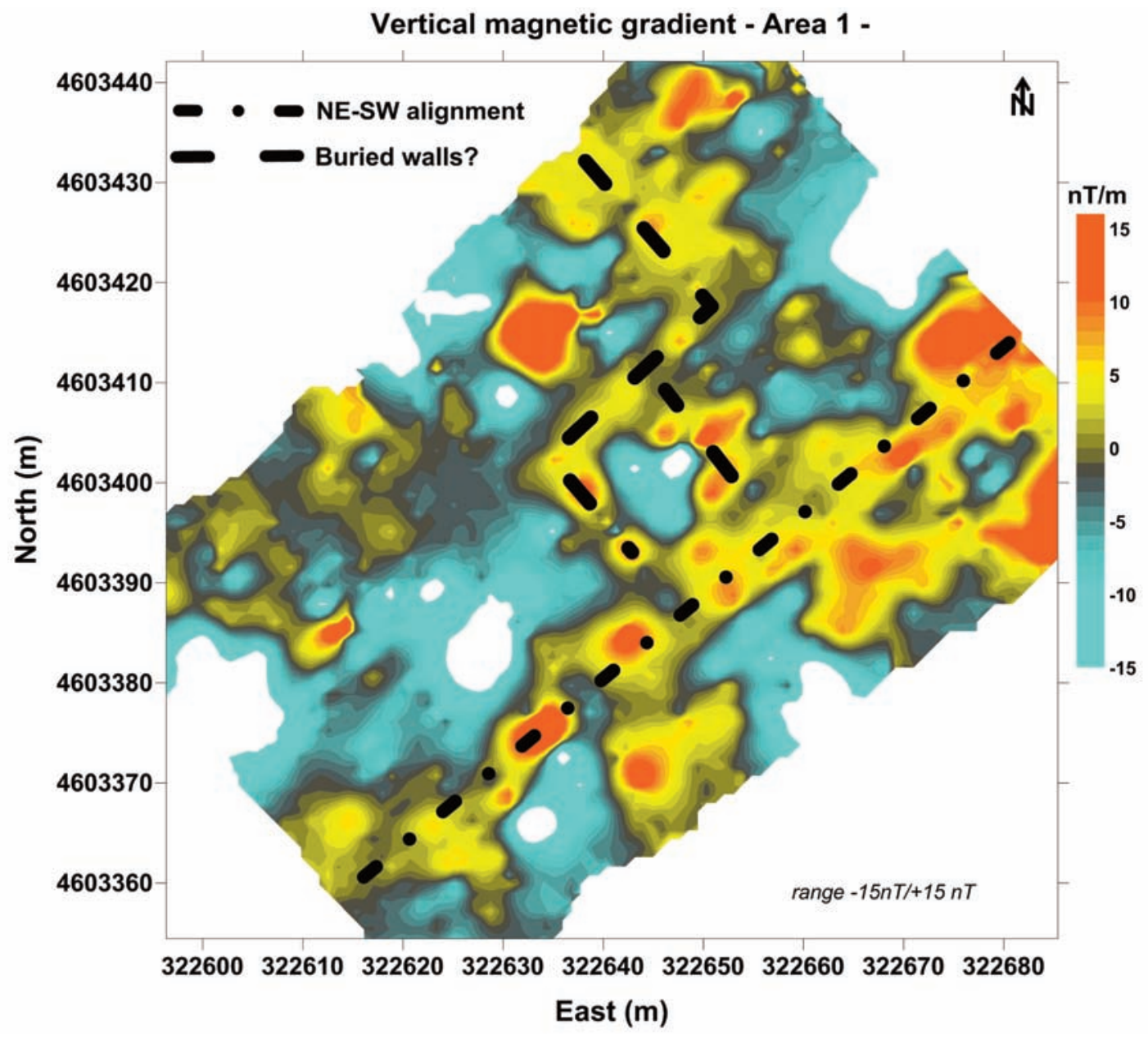

Figure 4. Map from the vertical magnetic gradient.

pipe, at about $1 \mathrm{~m}$ deep. Indeed, this affected all of the profiles, providing a well-aligned structure in a NE-SW direction, perpendicular to the Appian way. Observing the map (Figure $2 \mathrm{~b}$ ), it is also possible to note two areas with relative high resistivities, which can thus be possibly ascribed to the presence of buried ruins (Figure $2 \mathrm{~b}$, black dashed boxes). Due to the introductory aim here, we focused the surveys with the other techniques in the northern parts, to determine the role of the pipe in the archeological context, even though there were also some interesting rectangular conductivity anomalies in the southern part. Moreover, a transition zone from an area of high to low resistivity (in the western part) is clearly visible also.

The radar profiles were carried out in two sub-areas (Figure 1), which were defined considering the results from the FDEM survey, and they were perpendicular to the anomaly alignment. Strong signal attenuation affected the GPR measures because of the soil characteristics (agricultural terrain) and conditions (wet). An example of the interpretation of the radargrams is shown in Figure 3a, where three adjacent profiles are shown (C12, C13 and C14). One clear hyperbolic anomaly occurs in each profile (yellow box), which is consistent across the profiles according to its phase changing, shape intensity and position (yellow dotted line). The migrated data allowed this anomaly to be ascribed to the presence of a pipe ( $\varnothing 0.20 \pm 0.02 \mathrm{~m}$ ) at a depth of about $0.7 \mathrm{~m}$ to $0.9 \mathrm{~m}$. Its position also confirms the data from the FDEM survey. Moreover, the change in the signal phase of $180^{\circ}$ allows it to be assumed to have a metallic nature. Observing the map (Figure $3 \mathrm{~b}$ ), the pipe anomalies show very good alignment, spreading out to a distance of $46 \mathrm{~m}$ from the origin of the grid (Figure 3b, 0 line). At the same time, these anomalies disappear where the FDEM map shows an abrupt change in the ground conductivity that leads to strong signal attenuation.

Other evident anomalies (Figure 3a, green boxes) can be ascribed to the presence of buried wall remains $(0.40 \mathrm{~m}$ thick), while the adjacent intense plane reflections (Figure $3 \mathrm{a}$, orange dotted line) can be related to the remains of a paved floor. The depth of the burial ruins varied from about $0.60 \mathrm{~m}$ for the tops of the walls, to about $1 \mathrm{~m}$ for the floors.

The map in Figure $3 \mathrm{~b}$ shows the extension and the location of all of the main recognizable anomalies from the GPR lines. Of course, the coarse line spacing hampered the very accurate reconstruction of the buried structures, although it was very effective in revealing them. Most of the anomalies referable to these buried structures are located into the first $30 \mathrm{~m}$ from the Appian way. 


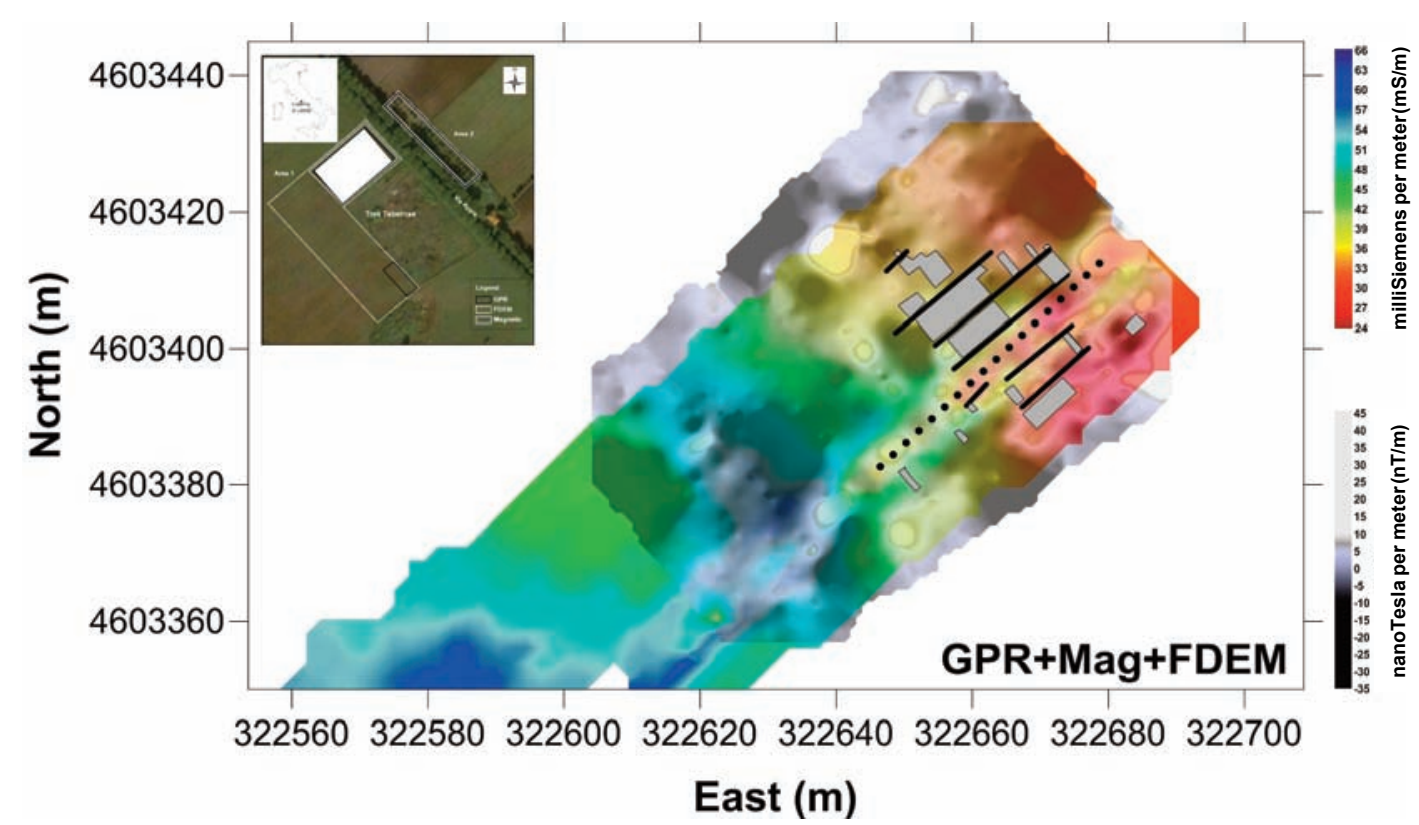

Figure 5. Map of the overlay of the FDEM and the GPR and magnetic methods. Inset, as for Figure 1, for direct comparison.

The map of the vertical gradient of the magnetic field is shown in Figure 4. This mainly covers the area defined by the GPR technique. The whole magnetic dataset was elaborated such as to emphasize the low intensity magnetic anomalies. Looking at the final map (Figure 4), an anomaly alignment in the NE-SW direction can be seen; the position of this confirms the hypothesis of the presence of the pipe suggested by both FDEM and the GPR method. The low intensity of the anomaly excludes its ferromagnetic origin, which might instead be related to a coating that has a different magnetic susceptibility compared to the ground. Other magnetic anomalies aligned in NW-SE and NE-SW directions are clearly visible in the map, with their consistency suggesting the presence of the remains of a buried wall.

Figure 5 shows an overlay of the results coming from these three different methods, with the maps overlaid on the basis of their differential GPS coordinates and on the coincidence of some common control points. The first important thing that is clearly evident in Figure 5 is that the anomalies from these different methods that relate to the pipe are perfectly superimposed. The density of the buried structures (from the GPR and magnetic methods) was higher where the FDEM survey showed higher relative resistivity values, confirming that FDEM as a very good survey-focusing tool. Moreover, the GPR profiles allowed the determination of some of the main characteristics of the pipe (diameter and depth), while its actual nature and extent can be evaluated by combining the FDEM and the magnetic data.

Considering all of the geophysical information, we can hypothesize that the pipe was made of lead (a nonferromagnetic metal), which was generally used for piping of water in antiquity. The calculated diameter from the GPR measurements is about $0.20 \mathrm{~m}$, and based on these characteristics, it is possible to ascribe the pipe to the centenaria type, the diameter of which was $0.21 \mathrm{~m}$ [Adam 1984, Mantelli and Temporelli 2007].

\section{Conclusions}

In the framework of the Mercator Project, an integrated geophysical survey was carried out at the site of Tres Tabernae (Latina, central Italy). As it is well known, geophysical methods for subsoil investigation are indirect, and are consequently affected by various levels of uncertainty. In this framework, the comparison of the different data represents an important point for the formulation of any final hypothesis.

This survey provided very good results, even if it was planned to be only preliminary and exploratory. Indeed, because of the many limitations, there was only one day available to acquire the most meaningful data in the surroundings of this previously excavated area.

The integration of the FDEM and the GPR and magnetic techniques indicates the presence of buried structures belonging to the Tres Tabernae statio. Moreover, the survey suggested that the information provided by each single technique was incomplete for the formulation of a proper hypothesis of the investigated site, with the determination of the pipe characteristics (diameter, depth, nature and extension) being a clear example of this.

Through this geophysical survey, new elements have been added to our knowledge of the extent of this archeological site. The anomalies indicated structures that can be referred to buried walls and floors, and in particular to the lead pipe. The proximity of these structures to those already excavated suggests the hypothesis of buildings (such as factories) referable to the hospitia. The possible presence of a centenaria pipe, which was probably carrying water from the Lepini Mounts [Barbetta 2008], would suggest that it was used for conducting water for the whole site and for the 
thermal bath. Based on this new evidence, Tres Tabernae can now be classified as a mansio rather than as a statio.

Encouraged by these good results, we would like to note that even an organized exploratory survey (five people at work for one day) has the chance to add useful information to an archeological task. Moreover, we hope that it will be possible in the future to find a way to plan for a very focused, high-resolution exploration of this area, and to start some small and cost-effective excavation campaigns.

\section{References}

Abramowitz, M. and I. Stegun (1972). Handbook of Mathematical Functions, Dover Publications, New York, 184 pp.

Adam, J.P. (1984). L'arte di costruire presso i Romani, Materiali e Tecniche, Longanesi \& Co., Milan, 369 pp.

Aspinall, A., C. Gaffney and A. Schmidt (2008). Magnetometry for Archaeologists, AltaMira Press, Lanham, 224 pp.

Barbetta, S. (2008). Il sistema dei trasporti nel territorio Pontino nell'antichità, In: Mercator: le vie dei mercanti, le città dei mercati nel Mediterraneo, Proceedings of the Symposium «Strutture e insediamenti antichi e medievali funzionali alla viabilità commerciale terrestre e marittima», edited by L. De Maria and A. Toro, Pieraldo Editore, Rome, 201-221.

Basile, V., M.T. Carrozzo, S. Negri, L. Nuzzo, T. Quarta and A.V. Villani (2000). A ground-penetrating radar survey for archaeological investigations in an urban area Lecce (Italy), J. Appl. Geophys., 44, 15-32.

Breiner, S. (1973). Applications Manual for Portable Magnetometers, GeoMetrics, Sunnyvale, CA., 58 pp.

Brizzolari, E., F. Ermolli, L. Orlando, S. Piro and L. Versino (1992). Integrated geophysical methods in archaeological surveys, J. Appl. Geophys., 29, 47-55.

Conyers, L.B. (2004). Ground Penetrating Radar for Archaeology, AltaMira Press, Walnut Creek, CA., 203 pp.

Francese, R.G., E. Finzi and G. Morelli (2009). 3-D high resolution multi-channel radar investigation of a Roman village in northern Italy, J. Appl. Geophys., 67, 44-51.

Hesse, A. (1999). Multi-parametric survey for archaeology: how and why, or how and why not?, J. Appl. Geophys., 41, 157-168.

Jordan, T. and D. Costantini (1999). The use of non-invasive electromagnetic (EM) techniques for focusing environmental investigations, In: Ground Conductivity Meters for Environmental Site Evaluation: Selected Papers and Examples, Geonics Ltd., 1-30.

Mantelli, F. and G. Temporelli (2007). L'acqua nella storia, FrancoAngeli, Milan, 359 pp.

Pérez Gracia, V., J.A. Canas, L.G. Pujades, J. Clapés, O. Caselles, F. Gracìa and R. Osorio (2000). GPR survey to confirm the location of ancient structures under the Valencian Cathedral (Spain), J. Appl. Geophys., 43, 167-174.

Piro, S., D. Goodman and Y. Nishimura (2001). High-resolution ground-penetrating radar survey at Forum NovumVescovio: studying urbanism in the Tiber valley, J. Roman Archaeol., 14, 59-79.

Seren, S., A. Eder-Hinterleitner, W. Neubauer, K. Löcker and P. Melichar (2007). Extended comparison of different GPR systems and antenna configurations at the Roman site of Carnuntum, Near Surf. Geophys., 5, 389-394.

Simpson, D., A. Lehouck, M.C. Meirvenne, J. Bourgeois, E. Thoen and J. Vervloet (2008). Geoarchaeological prospection of a medieval manor in the Dutch polders using and electromagnetic induction sensor in combination with soil augerings, Geoarchaeology, 23, 305-319.

Smekalova, T.N., O. Voss and S.L. Smekalov (2008). Magnetic Surveying in Archaeology. More than 10 years of using the Overhauser GSM-19 gradiometer, Wormianum.

Tite, M.S. and C.E. Mullins (1970). Electromagnetic prospecting on archaeological sites using a soil conductivity meter, Archaeometry, 12, 97-104.

Urbini, S., L. Cafarella, M. Marchetti, P. Chiarucci and D. Bonini (2007). Fast geophysical prospecting applied to archaeology: results at "Villa ai Cavallacci» (Albano Laziale, Rome) site, Annals of Geophysics, 50 (3), 291-299.

Weymounth, J.W. and R. Huggins (1985). Geophysical surveying of archaeological site, In: Archaeological Geology, edited by G. Rapp and J. A. Gifford, Yale University Press, New Haven, 191-235.

\footnotetext{
${ }^{\star}$ Corresponding author: Carla Bottari, Istituto Nazionale di Geofisica e Vulcanologia, Sezione Roma 2, Rome, Italy; e-mail: carla.bottari@ingv.it.
}

(C) 2010 by the Istituto Nazionale di Geofisica e Vulcanologia. All rights reserved. 